\title{
Article
}

\section{Effect of Conjugation Length on Photoinduced Charge- Transfer in \#-Conjugated Oligomer-Acceptor Dyads}

\author{
Junlin Jiang, Amani A. Alsam, Shanshan Wang, Shawkat M \\ Aly, Zhenxing Pan, Omar F. Mohammed, and Kirk S. Schanze \\ J. Phys. Chem. A, Just Accepted Manuscript • Publication Date (Web): 25 May 2017
}

Downloaded from http://pubs.acs.org on May 30, 2017

\section{Just Accepted}

"Just Accepted" manuscripts have been peer-reviewed and accepted for publication. They are posted online prior to technical editing, formatting for publication and author proofing. The American Chemical Society provides "Just Accepted" as a free service to the research community to expedite the dissemination of scientific material as soon as possible after acceptance. "Just Accepted" manuscripts appear in full in PDF format accompanied by an HTML abstract. "Just Accepted" manuscripts have been fully peer reviewed, but should not be considered the official version of record. They are accessible to all readers and citable by the Digital Object Identifier (DOIB). "Just Accepted" is an optional service offered to authors. Therefore, the "Just Accepted" Web site may not include all articles that will be published in the journal. After a manuscript is technically edited and formatted, it will be removed from the "Just Accepted" Web site and published as an ASAP article. Note that technical editing may introduce minor changes to the manuscript text and/or graphics which could affect content, and all legal disclaimers and ethical guidelines that apply to the journal pertain. ACS cannot be held responsible for errors or consequences arising from the use of information contained in these "Just Accepted" manuscripts. 


\title{
Effect of Conjugation Length on Photoinduced Charge-Transfer in $\pi$-Conjugated Oligomer-Acceptor Dyads
}

\author{
Junlin Jiang ${ }^{\dagger}$, Amani Alsam ${ }^{\S}$, Shanshan Wang ${ }^{\dagger}$, Shawkat M. Aly ${ }^{\S}$, Zhengxin Pan ${ }^{\dagger}$, \\ Omar F. Mohammed ${ }^{\S *}$, Kirk S. Schanze ${ }^{\dagger \neq^{*}}$ \\ $\dagger$ Department of Chemistry and Center for Macromolecular Science and Engineering, University \\ of Florida, P.O. Box 117200, Gainesville, Florida 32611-7200, United States \\ $\S$ Solar and Photovoltaics Engineering Research Center, Division of Physical Sciences and \\ Engineering, King Abdullah University of Science and Technology (KAUST), Thuwal 23955- \\ 6900, Kingdom of Saudi Arabia \\ \# Department of Chemistry, University of Texas at San Antonio, One UTSA Way, San Antonio, \\ TX 78249
}

\begin{abstract}
A series of $\pi$-conjugated oligomer-acceptor dyads were synthesized that feature oligo(phenylene ethynylene) (OPE) conjugated backbones end-capped with a naphthalene diimide (NDI) acceptor. The OPE segments vary in length from 4 to 8 phenylene ethynene units (PEn-NDI, where $\mathrm{n}=4,6$ and 8). Fluorescence and transient absorption spectroscopy reveals that intramolecular OPE $\rightarrow$ NDI charge transfer dominates the deactivation of excited states of
\end{abstract}


the PEn-NDI oligomers. Both charge separation (CS) and charge recombination (CR) are strongly exothermic $\left(\Delta \mathrm{G}_{\mathrm{CS}}^{0} \sim-1.1\right.$ and $\left.\Delta \mathrm{G}_{\mathrm{CR}}^{0} \sim-2.0 \mathrm{eV}\right)$, and the driving forces do not vary much across the series because the oxidation and reduction potentials and singlet energies of the OPEs do not vary much with their length. Bimolecular photoinduced charge transfer between model OPEs that do not contain the NDI acceptors with methyl viologen was studied, and the results reveal that the absorption of the cation radical state $\left(\mathrm{OPE}^{+\bullet}\right)$ remains approximately constant $(\lambda \sim 575 \mathrm{~nm})$ regardless of oligomer length. This finding suggests that the cation radical (polaron) of the OPE is relatively localized, effectively occupying a confined segment of $\mathrm{n} \leq 4$ repeat units in the longer oligomers. Photoinduced intramolecular electron transfer dynamics in the PEn-NDI series was investigated by UV-visible femtosecond transient absorption spectroscopy with visible and mid-infrared probes. Charge separation occurs on the $1-10 \mathrm{ps}$ timescale, with the rates decreasing slightly with increased oligomer length $\left(\beta_{\mathrm{CS}} \sim 0.15 \AA^{-1}\right)$. The rate for charge-recombination decreases in the sequence PE4-NDI > PE6-NDI $\sim$ PE8-NDI. The discontinuous distance dependence in the rate for charge recombination may be related to the spatial localization of the positive polaron state in the longer oligomers.

\section{INTRODUCTION}

Electron and energy transfer are fundamental processes involved in many important chemical and biological processes, ranging from light harvesting to energy conversion and storage. Over the past several decades, significant effort has been devoted to the design and study of molecular assemblies to study electron and energy transfer processes. ${ }^{1-3}$ The knowledge gained has been applied to develop molecular based devices such as dye-sensitized solar cells, organic solar cells, and artificial photosynthesis cells. ${ }^{4-6}$ A number of investigations have sought to understand the effect of $\pi$-conjugated spacers on electronic coupling and electron (or hole) transfer across the spacers in donor-bridge-acceptor (D-B-A) molecular assemblies. ${ }^{7}$ These investigations have sought to understand the role of the $\pi$-conjugated spacer in mediating charge transport. There is also the long-term goal of producing long lived radical ion pair (charge separated) states, aiming at applications to molecular electronics ${ }^{8}$ or artificial photosynthesis. ${ }^{1}$ 
These D-B-A systems consist of a donor (D) and acceptor (A) which are covalently linked via a molecular bridge (B). ${ }^{7}$

Electron transfer dynamics in many donor-bridge-acceptor (D-B-A) systems have been reported in which the bridge is a $\pi$-conjugated moiety. For example Wasielewski and co-workers explored electron transfer across oligo(p-phenylene) bridges in a D-B-A system featuring a perylene diimide acceptor and phenothiazine as the donor. ${ }^{9}$ Albinsson and co-workers carried out systematic investigations of electron transfer in porphyrin-based D-B-A systems in with the bridge was a series of oligo(phenylene ethynylene)s with varying length. ${ }^{10-11}$ Other donorbridge-acceptor (D-B-A) systems that have been explored include donor-acceptor pairs such as tetracene-pyromellitimide ${ }^{12}$ and porphyrin- $\mathrm{C}_{60},{ }^{13}$ and various $\pi$-conjugated oligomers have been used as bridges to link donor /acceptors in D-B-A systems, including oligo(phenylene vinylenes) $(\mathrm{OPV}),{ }^{12,14}$ oligo(phenylene ethynylene) (OPE), ${ }^{10-11,15}$ oligofluorene ${ }^{16-18}$ and oligothiophene. ${ }^{19}$ The active nature of the conjugated bridges in mediating electronic coupling is underscored by the relatively low attenuation factors $(\beta)$ observed across these spacers, ${ }^{10}$ where the attenuation factor reflects the strength of the exponential decay of the electron transfer rate, e.g.,

$$
\mathrm{k}_{\mathrm{ET}}=\mathrm{k}_{0} \exp \left(-\beta \mathrm{r}_{\mathrm{DA}}\right)
$$

where $\mathrm{k}_{\mathrm{ET}}$ is the electron transfer rate constant, and $\mathrm{k}_{0}$ is the maximum rate, and $\mathrm{r}_{\mathrm{DA}}$ is the donoracceptor separation distance.

Despite considerable work on electron transfer across $\pi$-conjugated oligomer bridges, there has been comparatively less investigation of the effect of $\pi$-conjugation on intramolecular electron transfer in D-A systems where a $\pi$-conjugated oligomer serves as the electron donor. This is surprising, given the importance of photoinduced electron transfer from a $\pi$-conjugated oligomer or polymer to an acceptor as the fundamental step in the mechanism for photovoltaic response in organic solar cells. There have been multiple studies of photoinduced processes in oligomer-(fullerene) acceptor systems; ${ }^{20-25}$ however, in most cases the results are at best ambiguous, due to the complex nature of fullerenes, which can act as both charge- and energyacceptors, and due to their broad absorption across the visible region, making photoselection difficult, and the low-energy fullerene triplet state.

In this report, we describe a detailed photophysical investigation of a series of naphthalene diimide (NDI) end-capped oligo(phenylene ethynylene)s (PEn-NDI, Chart 1). These structures were designed to allow investigation of the dynamics of photoinduced charge-separation and 
recombination resulting from photoexcitation of the oligo(phenylene ethynylene) (OPE) chromophore, followed by photoinduced electron transfer to the NDI acceptor,

$$
\mathrm{OPE}-\mathrm{NDI}+\mathrm{h} v \rightarrow{ }^{1} \mathrm{OPE}^{*}-\mathrm{NDI} \rightarrow\left(\mathrm{OPE}^{+}\right)-\left(\mathrm{NDI}^{-}\right) \rightarrow \text { OPE-NDI }
$$

In the PEn-NDI series, the OPE segment length was varied from $n=4$ to $n=8$ phenylene ethynylene repeat units, in order to examine the effect of $\pi$-conjugation in the donor on the dynamics of the forward and return electron transfer processes. The naphthalene diimide acceptor was used due to its relatively low reduction potential, combined with relatively high singlet and triplet energies, which preclude OPE to NDI energy transfer from competing with electron transfer. ${ }^{26-27}$ In addition, the NDI anion radical ( $\mathrm{NDI}^{-}$) has distinct absorption features which are easily identified by visible transient absorption spectroscopy. ${ }^{28}$

At the outset of this investigation we were interested in whether localization/delocalization and/or mobility of the singlet exciton and the polaron on the OPE chain (in the charge separated state) would influence the dynamics of forward or return charge transfer. Specifically, it is known that excited and charged states of $\pi$-conjugated oligomers and polymers are confined to specific segments by self-localization that occurs due to inner sphere and outer sphere relaxations. This localization may influence the electronic coupling between the donor and acceptor states, possibly resulting in interesting effects concerning the distance dependence of forward and return electron transfer reactions. The results described here reveal that photoinduced forward and back electron transfer reactions are efficient in all of the PEn-NDI series, and there are distinct variations in the observed rates with OPE segment length. The results are interpreted with a model that includes a description of the effect of singlet exciton delocalization on the rate of forward electron transfer, and a suggestion that positive polaron localization may influence the rate of return electron transfer in the charge separated state.

\section{Experimental}

\section{Methods and Instrumentation}

${ }^{1} \mathrm{H}-\mathrm{NMR}$ (300 or $500 \mathrm{MHz}$ ) and ${ }^{13} \mathrm{C}-\mathrm{NMR}(75.4$ or $125.7 \mathrm{MHz}$ ) spectra were obtained on either a Varian Mercury 300 or a Varian Inova 500 spectrometer utilizing $\mathrm{CDCl}_{3}$ or $\mathrm{CD}_{2} \mathrm{Cl}_{2}$ as solvents. ${ }^{1} \mathrm{H}$ NMR data recorded with residual internal $\mathrm{CD}_{2} \mathrm{Cl}_{2}(\delta 5.32)$ or $\mathrm{CDCl}_{3}(\delta 7.26) .{ }^{13} \mathrm{C}$ NMR data recorded with references $\mathrm{CD}_{2} \mathrm{Cl}_{2}\left(\delta\right.$ 53.84) or $\mathrm{CDCl}_{3}(\delta 77.16)$. High-resolution mass spectrometry was performed with either an Agilent 6200 ESI-TOF or an AB Sciex 5800 MALDI TOF/TOF in Chemistry Department at University of Florida. 
UV-visible absorption measurements were carried out on a Shimadzu UV-1800 dual beam absorption spectrophotometer. Photoluminescence spectra were recorded on a spectra fluorimeter from Photon Technology International (PTI). Photoluminescence lifetimes were obtained by time-correlated single photon counting (TCSPC) using a Fluo Time 100 (Picoquant), and excitation was provided using a PDL 800-B Picosecond Pulsed Diode Laser (375 nm). All the photophysical studies, including UV-visible absorption emission spectra, and TCSPC were measured in chloroform, unless otherwise specified. Fluorescence quantum yields were reported relative to quinine sulfate in $0.1 \mathrm{M} \mathrm{H}_{2} \mathrm{SO}_{4}$ aqueous solution as standard $\left(\Phi_{\mathrm{fl}}=0.54\right){ }^{29}$ and estimated to have $\pm 10 \%$ error. Singlet oxygen quantum yield measurements were conducted in deuterated chloroform under 10 mins of purging with oxygen, and reported relative to terthiophene as standard $\left(\Phi_{\Delta}=84 \%\right){ }^{30}$

The cyclic voltammetry (CV) and differential pulse voltammetry (DPV) experiments were performed using a Bioanalytical Systems CV50W electrochemical analyzer at a sweep rate of $100 \mathrm{mV} / \mathrm{s}$. The three-electrode setup consists of a platinum microdisk $\left(2 \mathrm{~mm}^{2}\right)$ working electrode, a platinum wire auxiliary electrode, and a silver wire reference electrode. Samples solutions $(0.5 \mathrm{mM})$ were prepared in dry dichloromethane with $0.1 \mathrm{M}$ tetrabutylammonium hexafuorophosphate $\left(\mathrm{TBAPF}_{6}\right)$ as a supporting electrolyte and degassed with argon flow prior to measurements. The electrochemical potentials were internally calibrated against the standard ferrocenium/ferrocene redox couple $\left(\mathrm{Fc}^{+} / \mathrm{Fc}=0.43 \mathrm{~V}\right.$ vs SCE in $\left.\mathrm{CH}_{2} \mathrm{Cl}_{2}\right)$.

Nanosecond transient absorption spectroscopy measurements were performed on an inhouse apparatus that is described in detail elsewhere. ${ }^{31}$ The third harmonic of a Continuum Surelite series Nd:YAG laser ( $\lambda=355 \mathrm{~nm}, 10 \mathrm{~ns}$ FWHM, $10 \mathrm{~mJ}$ per pulse) was used as the excitation source. Probe light was produced by a xenon flash lamp and the transient absorption signal was detected with a gated-intensified CCD mounted on a $0.18 \mathrm{M}$ spectrograph (Princeton PiMax/Acton Pro 180). The optical density of the solutions was adjusted to $\sim 0.7$ at the excitation wavelength $(355 \mathrm{~nm})$. Samples were measured in a cell that holds a total volume of 10 $\mathrm{ml}$ and the content was continuously re-circulated through the pump-probe region of the cell. Samples were prepared in solvents (THF or mixture solvents of THF and acetonitrile (v:v 33\%:67\%) and degassed by bubbling argon for $45 \mathrm{~min}$ before the acquisition. The transient absorption (TA) spectrum was collected from $350 \mathrm{~nm}$ to $850 \mathrm{~nm}$ with a $20 \mathrm{~ns}$ initial camera delay and with different subsequent delay time increments depending on the triplet lifetime of 
the molecule. Fifty averages were obtained at each delay time. Time-resolved spectra were analyzed by Global Kinetic Analysis using the Specfit/32 software package (Biologic SAS, www.bio-logic.info/rapid-kinetics/specfit.html).

Ultrafast pump-probe experiments were performed with femtosecond (fs) transient absorption spectroscopy with broadband capabilities. ${ }^{32}$ Briefly, an Ultrafast Systems Helios femtosecond transient absorption spectrometer equipped with UV-visible and near-IR detectors was used to measure the samples in this study. White-light-continuum probe pulse was generated in a $2 \mathrm{~mm}$ thick sapphire plate in an Ultrafast System LLC spectrometer using a few $\mu \mathrm{J}$ pulse energy of the fundamental output of a Ti:sapphire fs regenerative amplifier operating at $800 \mathrm{~nm}$ with $35 \mathrm{fs}$ pulses and a repetition rate of $1 \mathrm{kHz}$. The pump pulses at $355 \mathrm{~nm}$ were created from fs pulses generated in an optical parametric amplifier (Newport Spectra-Physics). The sample solution was constantly stirred to avoid photodegradation in the scanned volume. The pump and probe beams were overlapped both spatially and temporally on the sample solution, and the transmitted probe light from the samples was collected on the broad-band UV-visible-near-IR detectors to record the time-resolved excitation-induced difference spectra.

Time-resolved IR experiments were carried out using a Helios-IR spectrometer with broadband capability (Ultrafast Systems, U.S.A.). The UV pump pulses at $400 \mathrm{~nm}$ were straightforwardly obtained by the second harmonic of a 120 fs Ti:sapphire regenerative amplifier operating at $1 \mathrm{kHz}$ (Spectra-Physics). The tunable mid-IR probe pulses were generated by difference frequency mixing of the signal and idler pulses from a near-infrared optical parametric amplifier. The experimental setup is detailed elsewhere. ${ }^{33}$ In the transient IR measurements, the photo-induced reaction was recorded on a solution of PEn-NDI in DCM pumped through a rotational cell with nominal thickness of $350 \mu \mathrm{m}$, ensuring that for every laser shot a fresh sample was excited. The optical density of the solution was $1 \mathrm{mOD}$ at $350 \mathrm{~nm}$ with $350 \mu \mathrm{m}$ spacer.

\section{Results and Discussion}

Oligomer structures, Synthesis, and Characterization. The series of $\pi$-conjugated oligomer-acceptor dyads, PEn-NDI $(n=4,6,8)$ were synthesized which feature a conjugated oligo(phenylene ethynylene) backbone as an electron donor capped with a naphthalene diimide derivative as an electron acceptor. The naphthalene diimide derivative was chosen for its capability to serve as a strong electron acceptor and because of its characteristic radical anion 
absorption features. ${ }^{26,28,34-35}$ Three corresponding model oligomers end-capped with a triisopropylsilyl (TIPS) unit, PEn-TIPS $(\mathrm{n}=4,6,8)$, were also prepared for control studies (Chart 1). The oligomers were mainly synthesized using Sonogashira reactions, and they were characterized by ${ }^{1} \mathrm{H}-\mathrm{NMR} /{ }^{13} \mathrm{C}-\mathrm{NMR}$ and high resolution mass spectroscopy. Complete details concerning the synthesis and characterization are provided in the Supporting Information.

\section{Chart 1.}

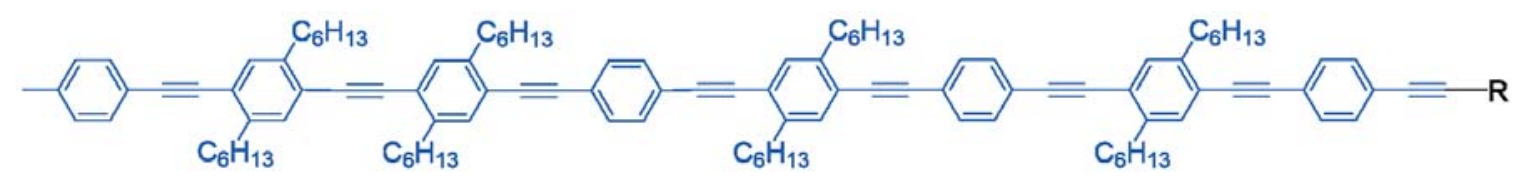

PE8-R

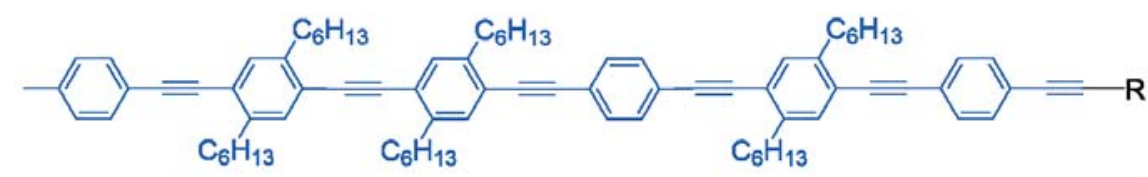

PE6-R

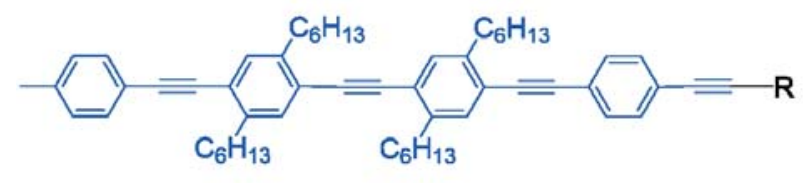

PE4-R

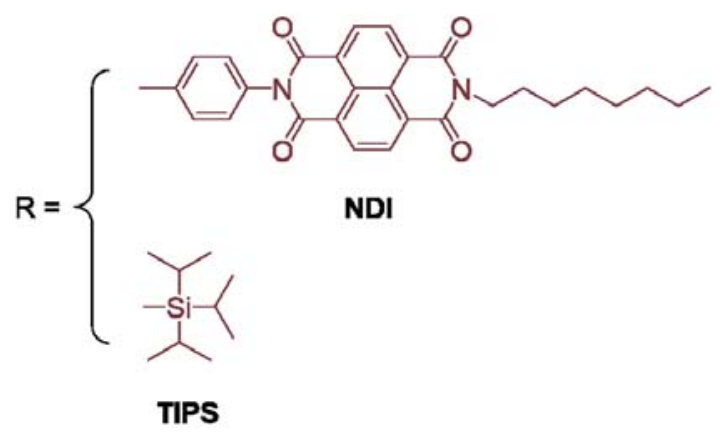

Photophysical Studies. The optical properties of the oligomers were studied by absorption and fluorescence spectroscopy in chloroform at room temperature, and the spectra of selected examples are illustrated in Figure 1. In general, all the PEn-NDI oligomers show combined absorption properties from both the PEn and NDI segments; however, the absorption is dominated by the oligo(phenylene ethynylene) backbones due to their relatively larger absorption coefficients (Figure 1). Taking PE4-NDI as an example, as shown by Figure 1A, PE4NDI has an intense absorption band at $300-400 \mathrm{~nm}$, with distinct peaks at $\sim 358$ and $\sim 378 \mathrm{~nm}$. The major UV-visible absorption is attributed to the PE4 segment, with superimposed features arising from the NDI moiety. When conjugation length increases from PE4 to PE8, the absorption spectra of PEn-TIPS and PEn-NDI oligomers red-shift and have increased molar absorptivity. Additionally, the mismatch of the emission from oligo(phenylene ethynylene) 
segments (see below) and absorption of the NDI moiety ensures the minimized energy transfer in the OPE-NDI system.
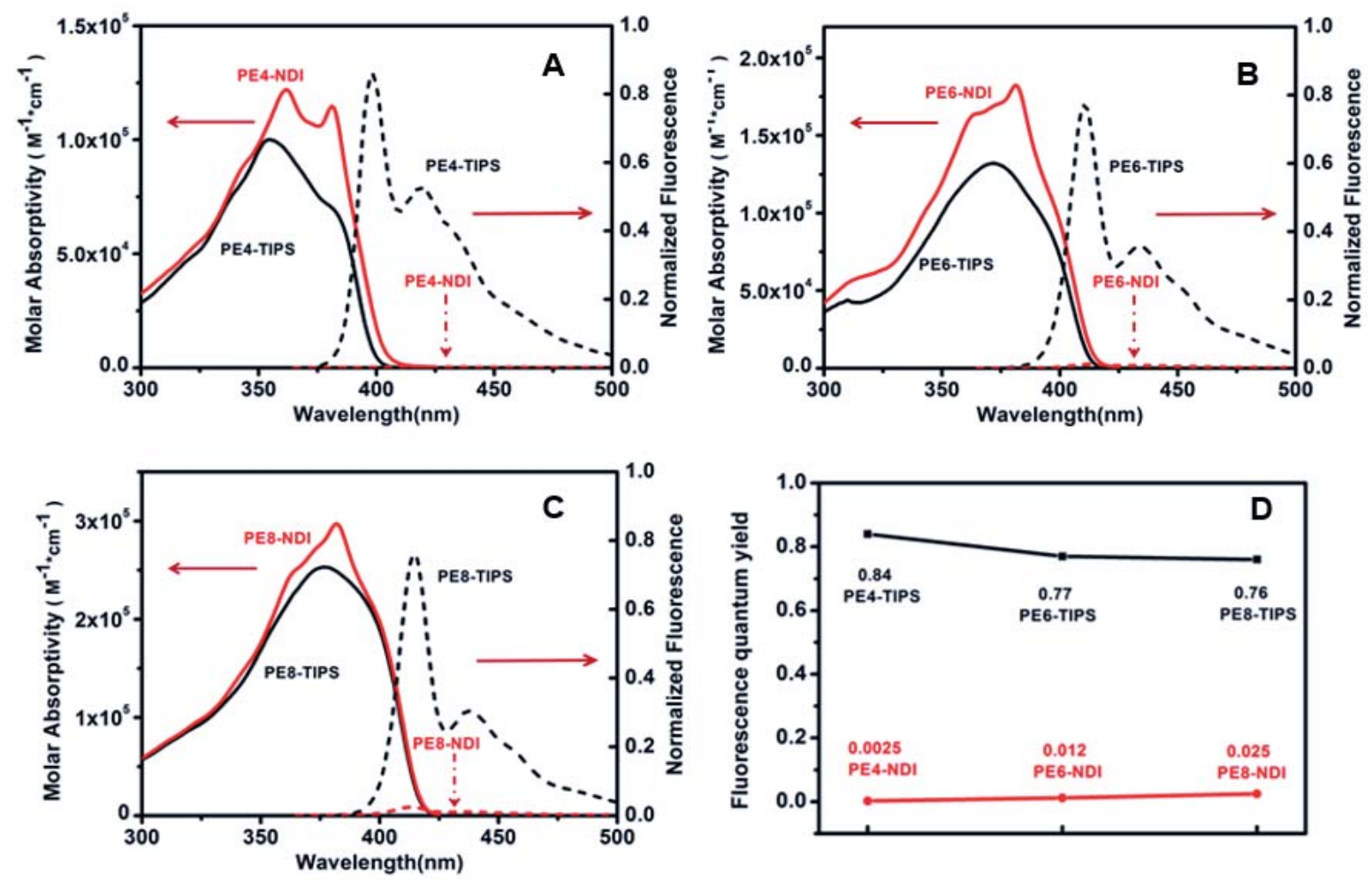

Figure 1. UV-visible absorption spectra of PEn-TIPS (black lines) and PEn-NDI (red lines); fluorescence emission spectra of PEn-TIPS (black dashed lines) and PEn-NDI (red dashed lines). Spectra measured in chloroform and the fluorescence spectra are normalized relative to the quantum yields. A) PE4-TIPS and PE4-NDI. B) PE6-TIPS and PE6-NDI. C) PE8-TIPS and PE8NDI. D) Plots of fluorescence quantum yields of PEn-TIPS and PEn-NDI.

All of the PEn-TIPS oligomers are highly emissive, and their fluorescence quantum yields $\left(\Phi_{1}\right)$ decrease slightly from $\sim 0.85$ to $\sim 0.76$ from PE4-TIPS to PE8-TIPS (quinine sulfate in $0.1 \mathrm{M} \mathrm{H}_{2} \mathrm{SO}_{4}$ aqueous solution as standard, $\left.\Phi_{\mathrm{f}}=0.54^{29}\right)$. Similarly, the PEn-TIPS oligomers feature decreasing fluorescence lifetimes with increased oligomer length, with $\tau_{\mathrm{f}}=\sim 0.82 \mathrm{~ns}$ down to $\sim 0.45$ ns from PE4-TIPS to PE8-TIPS (Table 1). The significant decrease in lifetime with increasing oligomer length implies that radiative decay rate increases with conjugation length. ${ }^{36}$ In stark contrast to the PEn-TIPS series, the PEn-NDI oligomers are virtually nonemissive: $\Phi_{\mathrm{f}}$ ranges from $\sim 0.002$ to $\sim 0.025$ from PE4-NDI to PE8-NDI (Figure 1D). Not 


\begin{tabular}{|c|c|c|c|c|c|c|c|c|c|}
\hline Oligomer $^{\mathrm{a}}$ & $\lambda_{\text {abs }} n m$ & $\varepsilon 10^{5} \mathrm{~cm}^{-1} \mathrm{M}^{-1}$ & $\lambda_{\mathrm{f}}^{\mathrm{b}} \mathrm{nm}$ & $\overline{\tau_{f}^{c} n s}$ & $\Phi_{\mathrm{f}}{ }^{\mathrm{d}}$ & $\tau_{\mathrm{T}}{ }^{\mathrm{e}} \mu \mathrm{s}$ & $\lambda_{T-T} \mathbf{n m}^{\mathrm{e}}$ & $\Phi_{\Delta}{ }^{f}$ & $\eta^{\mathrm{g}}$ \\
\hline PE4-TIPS & 354 & 1.08 & 398 & 0.82 & 0.84 & 3.45 & 623 & 0.19 & -- \\
\hline PE4-NDI & 362 & 1.21 & 412 & -- & 0.0021 & -- & -- & -- & 0.998 \\
\hline PE6-TIPS & 372 & 1.32 & 410 & 0.51 & 0.77 & 4.17 & 696 & 0.10 & -- \\
\hline PE6-NDI & 381 & 1.82 & 413 & -- & 0.012 & -- & -- & -- & 0.984 \\
\hline PE8-TIPS & 377 & 2.53 & 415 & 0.45 & 0.76 & 3.13 & 712 & 0.08 & -- \\
\hline PE8-NDI & 382 & 2.97 & 413 & -- & 0.025 & -- & -- & -- & 0.967 \\
\hline NDI & 381 & 0.51 & 403 & -- & 0.0018 & -- & -- & -- & -- \\
\hline
\end{tabular}

surprisingly, the fluorescence lifetimes for all the NDI capped oligomers were below the instrument response $(<100 \mathrm{ps})$.

Table 1. Photophysical Properties of Oligomers

\footnotetext{
${ }^{a}$ All photophysical data was obtained in chloroform solutions. ${ }^{b}$ The excitation wavelength for all fluorescence studies is $355 \mathrm{~nm}$. ${ }^{\mathrm{c}}$ Fluorescence lifetime measured by TCSPC. ${ }^{\mathrm{d}}$ Quinine sulfate in $0.1 \mathrm{M} \mathrm{H}_{2} \mathrm{SO}_{4}$ aqueous solution as standard $(\Phi \mathrm{fl}=0.54) .{ }^{29}{ }^{2}$ Measured by nanosecond transient absorption spectroscopy in a mixture of THF and acetonitrile (v:v 66:34). ${ }^{\mathrm{f}}$ Measured in deuterated chloroform, with terthiophene as standard $\left(\Phi_{\Delta}=84 \%\right) .{ }^{30} \mathrm{~g}$ Electron transfer efficiencies $(\eta)$ were calculated as $\eta=1-\Phi_{\mathrm{fl}}(\mathrm{PEn}-\mathrm{NDI}) / \Phi_{\mathrm{fl}}(\mathrm{PEn}-\mathrm{TIPS})(\mathrm{n}=4$, $6,8)$.
}

The low fluorescence quantum yields for PEn-NDI oligomers indicate efficient quenching of the singlet excited state, presumably due to excited state electron transfer from the donor (OPE) to acceptor group (NDI). The electron transfer efficiency can be estimated from eq. 3 ,

$$
\eta=1-\Phi_{\mathrm{f}}(\mathrm{PEn}-\mathrm{TIPS}) / \Phi_{\mathrm{f}}(\mathrm{PEn}-\mathrm{NDI})
$$

where $\Phi_{\mathrm{f}}(\mathrm{PEn}-\mathrm{NDI})$ is the fluorescence quantum yield for the PEn-NDI oligomers and $\Phi_{\mathrm{f}}(\mathrm{PEn}-$ TIPS) is the quantum yield for corresponding PEn-TIPS oligomers. As a result, all the three PEnNDI oligomers exhibit high electron transfer efficiency, ranging from $99.8 \%$ to $96.7 \%$ with increased oligomer length (Table 1). The highly efficient charge separation properties make the PEn-NDI oligomers excellent targets to investigate their charge separation and recombination kinetics and how they are influenced by the oligomer/donor conjugation length. 
Singlet-triplet intersystem crossing is one possible pathway for the deactivation of the excited states in OPEs. ${ }^{37}$ In the present work, nanosecond transient absorption spectroscopy (nsTA) was carried out to characterize the triplet transient absorption properties for PEn-TIPS and PEn-NDI oligomers. For these experiments the optical density for all the oligomer solutions was 0.7 at the excitation wavelength $(355 \mathrm{~nm})$ in THF. As shown in Figure 2, all the three PEn-TIPS oligomers exhibit moderately intense transient absorption $(500-700 \mathrm{~nm})$ that persists into the $\mu \mathrm{s}$ time domain. The spectra are similar to those previously assigned to the triplet state of oligo(phenylene ethynylene)s, and by analogy they are assigned to the triplet excited states of the PEn-TIPS oligomers. ${ }^{37-38}$ Interestingly, excitation of the PEn-NDI oligomers under the same conditions does not give rise to transient absorption that can be observed on timescales longer than $20 \mathrm{~ns}$. The lack of a triplet absorption is consistent with rapid photoinduced charge transfer taking place from the singlet state, which quenches triplet formation (vide infra). Interestingly, with $\mathrm{n}$ increasing from 4 to 8 for PEn-TIPS oligomers, the triplet transient absorption peak is red-shifted from $623 \mathrm{~nm}$ to $712 \mathrm{~nm} .{ }^{38}$ At the same time, the transient absorption intensity decreases with increasing oligomer length; this finding is consistent with earlier work on OPEs showing a reduced triplet yield with increased oligomer length. ${ }^{37-38}$ The results from singlet oxygen quantum yield studies of PEn-TIPS oligomers are consistent with trends observed from triplet-triplet transient absorption data, in particular, PE4-TIPS exhibits singlet oxygen quantum yield of 0.19 , followed by 0.10 for PE6-TIPS, and 0.08 for PE8-TIPS (see Supporting Information, Figure S1).

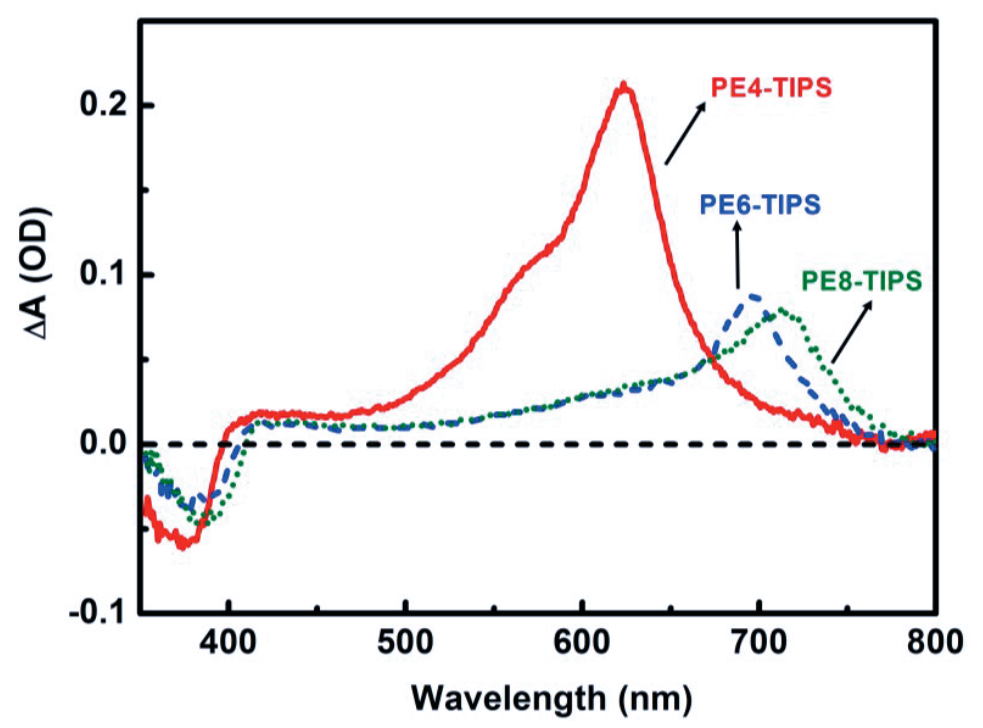


Figure 2. Nanosecond transient absorption spectra of PEn-TIPS $(\mathrm{n}=4,6,8)$. The optical densities for all the oligomers were 0.7 at $355 \mathrm{~nm}$ in THF. Transient absorption spectra were obtained at $20 \mathrm{~ns}$ after laser $10 \mathrm{~ns}$ pulsed excitation at $355 \mathrm{~nm}$.

Energetics of Photoinduced Electron Transfer. In order to estimate the energies of the charge-separated states for the PEn-NDI oligomers, cyclic voltammetry and differential pulse voltammetry (CV and DPV) were performed in dichloromethane. CV and DPV data are shown in the Supporting Information (Figure S2), and a tabular listing of results is provided in Table 2. Note that all potentials listed are relative to $\mathrm{Fc}^{+} / \mathrm{Fc}$. The cyclic voltammetry of PE4-NDI features two reversible cathodic waves at $-1.05 \mathrm{~V}$ and $-1.48 \mathrm{~V}$, along with a single irreversible anodic wave at $\mathrm{E}_{\mathrm{ox}} \approx 1.04 \mathrm{~V}$. The other NDI capped oligomers give similar results (Table 2). The reduction waves are clearly due to the NDI centred one- and two-electron processes, ${ }^{27-28}$ while the oxidation is due to the OPE segment.

The driving force for charge separation from the singlet excited states in the PEn-NDI series can be approximated by using eq. $4,{ }^{39-40}$

$$
\Delta \mathrm{G}_{\mathrm{CS}}^{0}=\mathrm{E}_{\text {ox }}^{0}-\mathrm{E}_{\text {red }}^{0}-\Delta \mathrm{E}_{0,0}-\mathrm{e}^{2} /\left(4 \pi \varepsilon_{0} \varepsilon \mathrm{R}_{\mathrm{DA}}\right)
$$

Where $\mathrm{E}_{\text {ox }}^{0}$ is the oxidation potential of the donor, $\mathrm{E}_{\text {red }}^{0}$ is the reduction potential of the acceptor, and $\Delta \mathrm{E}_{0,0}$ is the singlet excited state energy. The last term is the Coulomb stabilization energy in the charge separated state, where $\varepsilon$ is the dielectric constant in the solvent $\left(8.93\right.$ in $\left.\mathrm{CH}_{2} \mathrm{Cl}_{2}\right)$ and $\mathrm{R}_{\mathrm{DA}}$ is the distance between the donor and acceptor units. (The separation distances were estimated as center-to-center using structures calculated from DFT B3LYP 6-31G* structures, Figure S3). The calculated driving forces, $\Delta \mathrm{G}^{0}{ }_{\mathrm{CS}}$, are listed in Table 2, and they range from -1.19 to $-1.10 \mathrm{eV}$ across the series. Note that $\Delta \mathrm{G}_{\mathrm{CS}}^{0}$ does not vary much across the series, and this is a reflection of the fact that the oxidation and reduction potentials and singlet energies do not vary much with oligomer length.

The driving for decay of the charge separated state, $\Delta \mathrm{G}_{\mathrm{CR}}^{0}$, is estimated by eq. 5 ,

$$
\Delta \mathrm{G}_{\mathrm{CR}}^{0}=-\left(\mathrm{E}_{\text {ox }}^{0}-\mathrm{E}_{\text {red }}^{0}-\mathrm{e}^{2} /\left(4 \pi \varepsilon_{0} \varepsilon \mathrm{R}_{\mathrm{DA}}\right)\right)
$$

where the terms are defined above. The driving force for recombination for all three PEn-NDI oligomers is estimated to range from -2.02 to $-1.96 \mathrm{eV}$ (Table 2). Taken together the thermodynamic data suggests that both charge separation and charge recombination are strongly exothermic, with the latter being considerable more exothermic. 
In order to complete the picture of the states involved in the photophysics of the PEn-NDI oligomers, it is necessary to pinpoint the triplet levels. Previous studies indicate that the singlettriplet splitting $\left(\Delta \mathrm{E}_{\mathrm{ST}}\right)$ in phenylene ethynylene conjugated systems is $\sim 0.75 \mathrm{eV}^{41}$ Using this value, combined with the singlet energies, we estimate that the triplet states in the PEn-NDI oligomers lie within the range $2.37-2.45 \mathrm{eV}$. It is important to note that the triplet states are higher in energy than the charge separated states in all of the PEn-NDI series.

Table 2. Thermodynamic Parameters for PEn-NDI Oligomers

\begin{tabular}{cccccccc}
\hline & $\mathbf{E}_{\mathbf{0 x}} / \mathbf{V}^{\mathbf{a}}$ & $\left(\mathbf{E}_{\mathbf{0 x}} / \mathbf{V}\right)^{\mathbf{b}}$ & $\mathbf{E}_{\text {red }} / \mathbf{V}^{\mathbf{a}}$ & $\left(\mathbf{E}_{\text {red }} / \mathbf{V}\right)^{\mathbf{b}}$ & $\Delta \mathbf{E}_{\mathbf{0}, 0}{ }^{\mathbf{c}}$ & $\Delta \mathbf{G}_{\mathrm{CS}}^{\mathbf{0}}{ }^{\mathbf{d}}$ & $\Delta \mathbf{G}^{\mathbf{0}}{ }_{\mathrm{CR}}{ }^{\mathbf{e}}$ \\
\hline PE4-NDI & 1.04 & $(0.98,1.24)$ & $-1.05,-1.48$ & $(-1.05,-1.48)$ & 3.20 & -1.19 & -2.01 \\
PE6-NDI & 1.03 & $(0.99)$ & $-1.05,-1.49$ & $(-1.07,-1.50)$ & 3.12 & -1.10 & -2.02 \\
PE8-NDI & 0.96 & $(0.91)$ & $-1.05,-1.51$ & $(-1.05,-1.51)$ & 3.12 & -1.16 & -1.96 \\
PE6-TIPS & 1.06 & $(0.97)$ & -- & -- & 3.12 & -- & -- \\
\hline
\end{tabular}

${ }^{a}$ Obtained from cyclic voltammetry measurements. ${ }^{b}$ Obatained from differential pulse voltammetry measurements. ${ }^{\mathrm{c}}$ Zero-zero transition energy, estimated on the basis of $\Delta \mathrm{E}_{0,0}=\left(\left(\mathrm{E}_{\mathrm{abs}(\max )}+\mathrm{E}_{\mathrm{em}(\max )}\right) / 2\right.$. ${ }^{\mathrm{d}}$ Calculated from equation 2-3. ${ }^{\mathrm{e}}$ Calculated from equations 2 - 4. $\left(\mathrm{E}_{\mathrm{ox}}\right.$ and $\mathrm{E}_{\mathrm{red}}$ were obtained from cyclic voltammetry measurements, Coulombic stabilization energies were calculated from Weller method, $0.05 \mathrm{eV}$ for PE8-NDI, $0.06 \mathrm{eV}$ for PE6-NDI and $0.08 \mathrm{eV}$ for PE4-NDI).

Scheme 1 below summarizes the states involve in the photophysics of the PEn-NDI oligomers, along with their approximate energies. The important aspect is that the charge separated state is at lower energy compared to the singlet and triplet states. Therefore, excited state decay of both states is anticipated to occur via the charge separated state.

\section{Scheme 1}




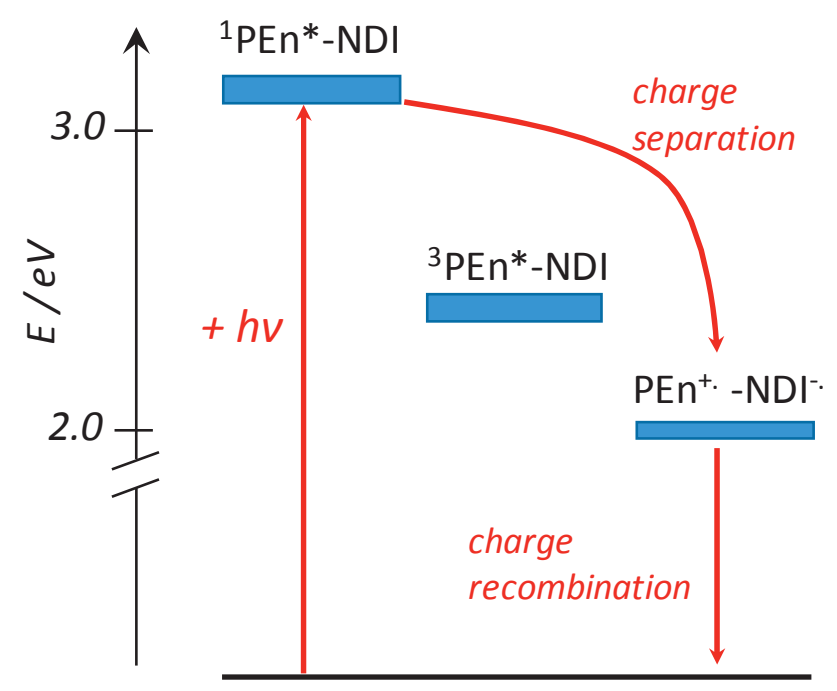

Intermolecular Photoinduced Charge Transfer. Intermolecular charge transfer between the PEn-TIPS oligomers and methyl viologen $\left(\mathrm{MV}^{2+}\right)$ was studied by nanosecond transient absorption (ns-TA) to gain insight concerning the spectra of the oligomer radical cations ( $\mathrm{OPE}^{+\bullet}$ ). The triplet excited PEn-TIPS oligomers are expected to transfer one electron to $\mathrm{MV}^{2+}$, forming $\mathrm{OPE}^{+\bullet}$ and $\mathrm{MV}^{+\bullet}$ radical cation, eq. 6 ,

$$
{ }^{1} \text { PEn-TIPS } * \rightarrow{ }^{3} \text { PEn-TIPS } *+\mathrm{MV}^{2+} \rightarrow \text { PEn-TIPS }^{+\bullet}+\mathrm{MV}^{+\bullet}
$$

Nanosecond-microsecond transient absorption was carried out on solutions of the PEn-TIPS oligomers $(7.0 \mu \mathrm{M})$ with $\mathrm{MV}^{2+}(1.0 \mathrm{mM})$ in a $\mathrm{THF} / \mathrm{CH}_{3} \mathrm{CN}$ solvent mixture (v:v 2:1). Qualitatively similar results were obtained for all of the oligomers, and Figure 3A shows the results for PE4-TIPS. The spectra for PE6-TIPS and PE8-TIPS are in the Supporting Information (Figure S4). At early times after excitation (20 ns), the spectrum is dominated by the triplettriplet absorption of PE4-TIPS $(\lambda \sim 610 \mathrm{~nm})$. However, over a time course of $2 \mu \mathrm{s}$, the triplet absorption decays, and there is a residual, blue-shifted absorption remaining ( $\lambda \sim 585 \mathrm{~nm})$. This absorption feature is accompanied by a narrow peak at $\lambda \sim 390 \mathrm{~nm}$. Taken together, the data suggests that the long time absorption is due to the products of photoinduced charge transfer, with the band in the red-arising from the radical cation, PE4-TIPS ${ }^{+}$, and the narrow peak in the near $\mathrm{UV}$ is due to $\mathrm{MV}^{+\bullet}{ }^{4243}$ By using principal component analysis, the time resolved absorption data for the three oligomers was analyzed to provide principal component (eigen)spectra for the short-lived and long-lived transients (e.g., assigned to ${ }^{3}$ PEn-TIPS* and PEn-TIPS ${ }^{+*}$, respectively). The resulting eigenspectra are summarized for the three oligomers in Figures $3 \mathrm{~B}$ 
and $3 \mathrm{C}$ Here it is easily seen that the absorption maximum of the triplet state systematically redshifts with increasing oligomer length (compare with Figure 2); by contrast, the absorption of the cation radical state, PEn-TIPS $^{+}$, remains approximately constant regardless of oligomer length. Importantly, the cation radical (polaron) state of the oligomers absorbs strongly in the visible region, with $\lambda \sim 575 \mathrm{~nm}$. The fact that the PEn-TIPS ${ }^{+\bullet}$ absorption is relatively constant across series suggests that the OPE polaron is spatially confined to a segment which is less than or equal to 4 phenylene ethynylene units. ${ }^{44}$

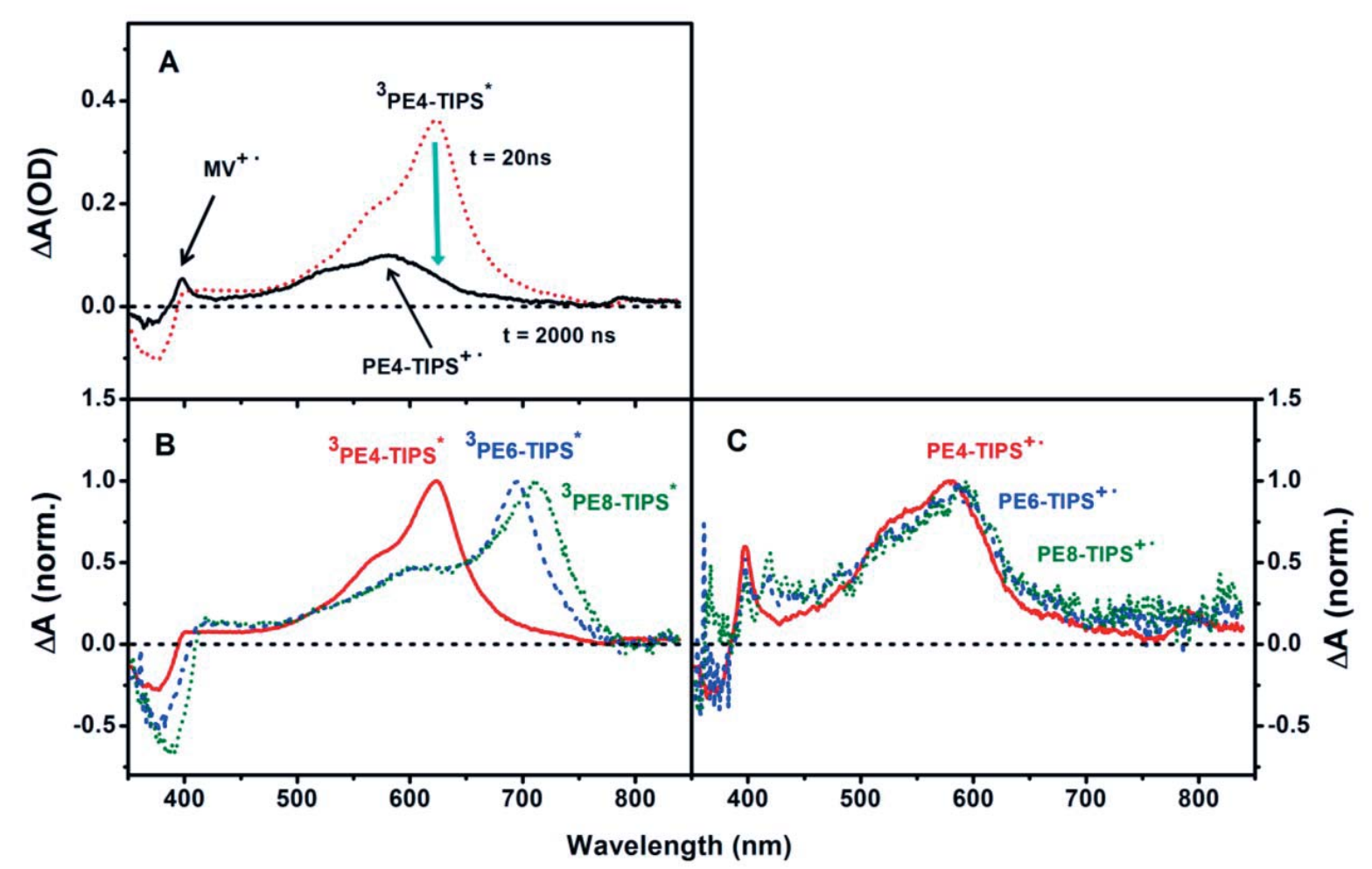

Figure 3. A) Nanosecond-microsecond transient absorption spectra for PE4-TIPS $(7.0 \mu \mathrm{M})$ with $\mathrm{MV}^{2+}(1.0 \mathrm{mM})$ at $20 \mathrm{~ns}$ and $2 \mu \mathrm{s}$ following $355 \mathrm{~nm}$ excitation (red dotted and black solid lines, respectively). B) Eigenspectra corresponding to triplet-triplet absorption of PE4-TIPS (red solid line), PE6-TIPS (blue dashed line) and PE8-TIPS (green dotted line). C) Eigenspectra corresponding to cation radical absorption of PE4-TIPS ${ }^{+\bullet}$ (red solid line), PE6-TIPS ${ }^{+\bullet}$ (blue dashed line) and PE8-TIPS ${ }^{+\bullet}$ (green dotted line). Transient absorption carried out in a solvent mixture of THF and acetonitrile (v:v 2:1) with optical density for oligomers at 0.7 at $355 \mathrm{~nm}$. Eigenspectra were obtained from principal component analysis of time resolved transient absorption spectra using SpecFit global analysis software. 
Photoinduced Electron Transfer in PEn-NDI Oligomers. UV-visible region femtosecond transient absorption spectroscopy was carried out to study the dynamics of photoinduced intramolecular electron transfer in the PEn-NDI oligomers. The experiments were carried out in $\mathrm{CH}_{2} \mathrm{Cl}_{2}$ solution with 35 fs pulsed excitation at $350 \mathrm{~nm}$. First, control experiments were carried out on the PEn-TIPS oligomers to characterize the singlet excited state absorption and dynamics (Figure S5). Here it can be seen that the singlet excited state, ${ }^{1}$ PEn-TIPS*, is characterized by an apparent bleach between $400-500 \mathrm{~nm}$ due to stimulated emission, ${ }^{45}$ coupled with a broad, featureless absorption that extends from the visible into the near-IR region due to excited state absorption (ESA). ${ }^{38,45}$ At longer times ( $\mathrm{t}>2 \mathrm{~ns}$ ) the absorption due to the triplet is clearly seen in the spectrum of PE4-TIPS. The excited state dynamics are shown in Figure S6, and it is seen that the ${ }^{1}$ PEn-TIPS ${ }^{*}$ states decay in $<1 \mathrm{~ns}$, consistent with the lifetimes obtained from fluorescence decay studies (Table 1).

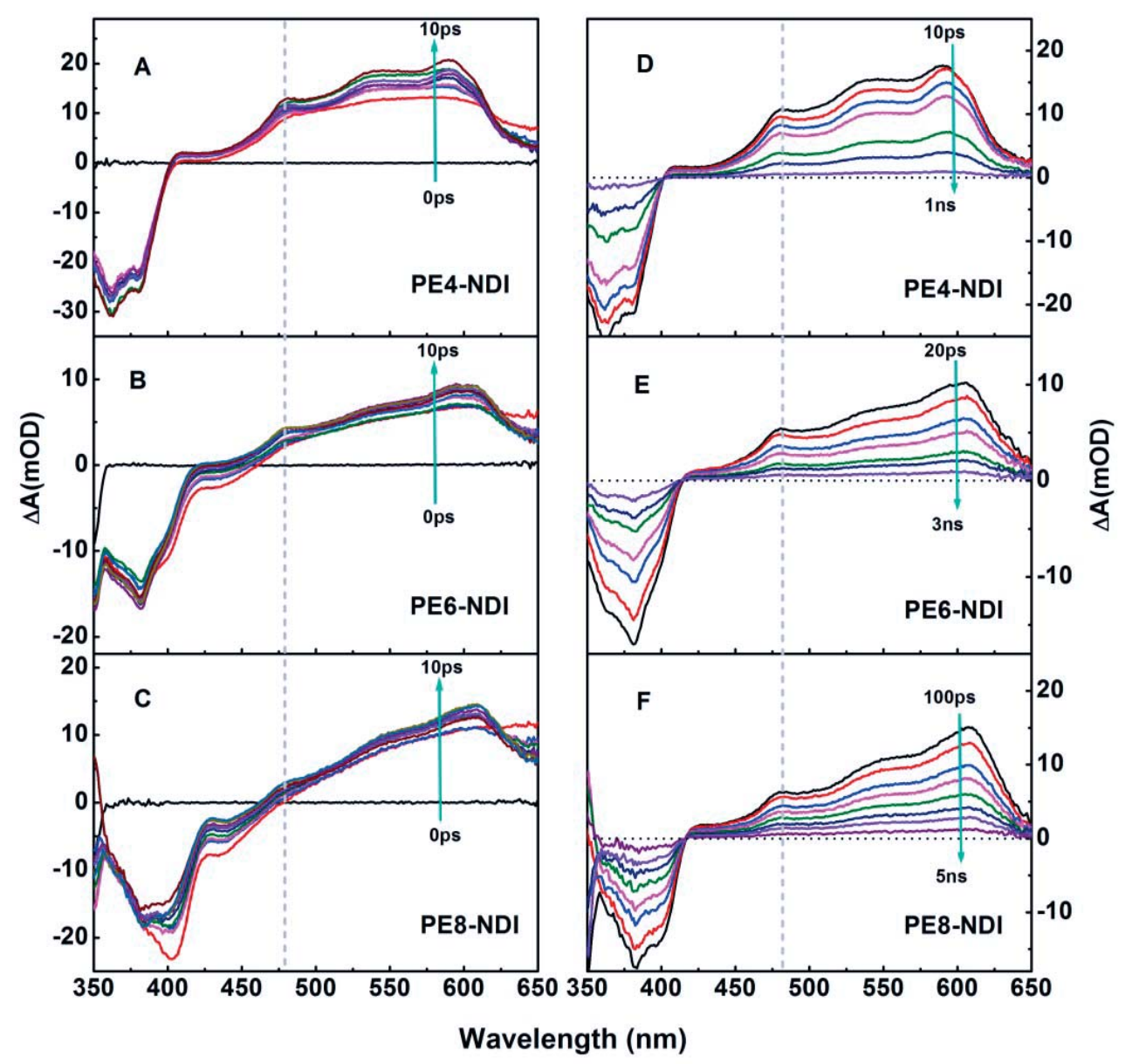


Figure 4. A, B, C: Transient absorption spectra for PEn-NDI series on $0-10$ ps timescale after excitation. D, E, F: Transient absorption spectra for PEn-NDI series on longer timescale (see inset). Samples were excited at $350 \mathrm{~nm}$ in dichloromethane. The dashed vertical line highlights $\mathrm{NDI}^{\bullet}$ absorption feature at $480 \mathrm{~nm}$.

The ultrafast transient absorption spectra of the PEn-NDI oligomers are distinctly different from that of the PEn-TIPS oligomers (Figure 4). For each of the oligomers, the spectra are characterized by a strong band with $\lambda_{\max } \sim 580-600 \mathrm{~nm}$, with a distinct narrow peak at shorter wavelength, $\lambda \sim 480 \mathrm{~nm}$. These absorption features are clearly due to the charge separated state, $\mathrm{PEn}^{+\bullet}-\mathrm{NDI}^{-\bullet}$, with the strong band in the red due to the OPE cation $\left(\mathrm{OPE}^{+}\right.$, compare Figure $\left.3 \mathrm{C}\right)$ and the short wavelength peak due to $\mathrm{NDI}^{-}{ }^{\cdot 28}$ Note also that consistent with the results obtained in the bimolecular electron transfer study with $\mathrm{MV}^{2+}$ acceptor (Figure 3C), the absorption in the $580-600 \mathrm{~nm}$ region that is attributed to the $\mathrm{OPE}^{+\bullet}$ is slightly blue shifted in PE4-NDI compared to the other two oligomers.

The transient absorption dynamics of the PEn-NDI oligomers provide insight regarding the rates of charge separation and recombination. As shown in Figure 5A, the kinetics at $480 \mathrm{~nm}$ (corresponding to $\mathrm{NDI}^{-}$) exhibit a rise on the $1-10 \mathrm{ps}$ timescale, and then a slower decay on timescales 1- 5 ns. The rise is attributed to charge separation and the decay to charge recombination, eqs. 7 and 8 , respectively.

$$
\begin{aligned}
& { }^{1} \mathrm{PEn}^{*} \text {-NDI } \rightarrow \mathrm{PEn}^{+\bullet} \text {-NDI }{ }^{-} \\
& \mathrm{PEn}^{+\bullet}{ }^{-}-\mathrm{NDI}^{-} \rightarrow \text { PEn-NDI }
\end{aligned}
$$

Fits of the dynamics provide quantitative information regarding the kinetics of electron transfer (Table 3). In particular, the rates for charge separation are very fast, ranging from $1-10 \times 10^{11}$ $\mathrm{s}^{-1}$, whereas the rates for charge recombination are slower by a factor of $\sim 100$, ranging from $0.8-$ $3 \times 10^{9} \mathrm{~s}^{-1}$. Note that the rates for charge separation decrease noticeably as the oligomer length increases. However, the dynamics for charge recombination are much less dependent on oligomer length, with a modest decrease between PE4-NDI and PE6-NDI, but then the rate is essentially the same for the longer two oligomers. 

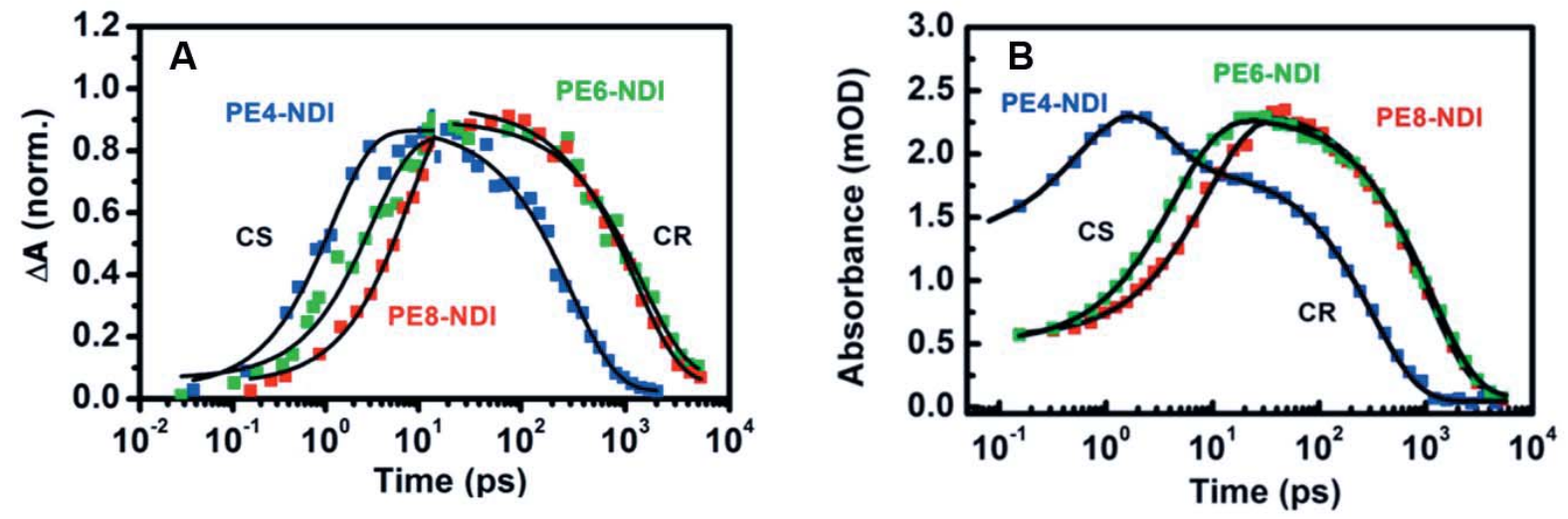

Figure 5. A) Visible region transient absorption dynamics of PEn-NDI monitored at $480 \mathrm{~nm}$. B) Mid-infrared transient absorption dynamics of PEn-NDI monitored at $2080 \mathrm{~cm}^{-1}$.

Mid-infrared transient absorption spectroscopy was also applied to probe the charge transfer processes in the PEn-NDI oligomers. ${ }^{33,46-48}$ In this case, the transients were monitored at 2080 $\mathrm{cm}^{-1}$ by using a mid-infrared probe continuum combined with a mid-infrared array detector. As shown in Figure 6, upon laser excitation, a transient absorption band at $\sim 2080 \mathrm{~cm}^{-1}$ is observed to grow in on a time-scale of 3 - 50 ps for all the PEn-NDI oligomers and it decays in a relatively slower process within the time-scale of $1-3.5 \mathrm{~ns}$. The transient absorption band at $2080 \mathrm{~cm}^{-1}$ is $70 \mathrm{~cm}^{-1}$ lower in frequency compared to the position of the $\mathrm{C} \equiv \mathrm{C}$ stretch for the ground state oligomers (see spectra for PE4-TIPS and PE4-NDI in Figure S7), and attributed to the internal acetylene vibration in radical cation $\left(\mathrm{OPE}^{+\bullet}\right)$ present in the charge separated state, an assignment that is supported by previous studies of phenylene ethynylene oligomer ion radicals. ${ }^{47}$ 


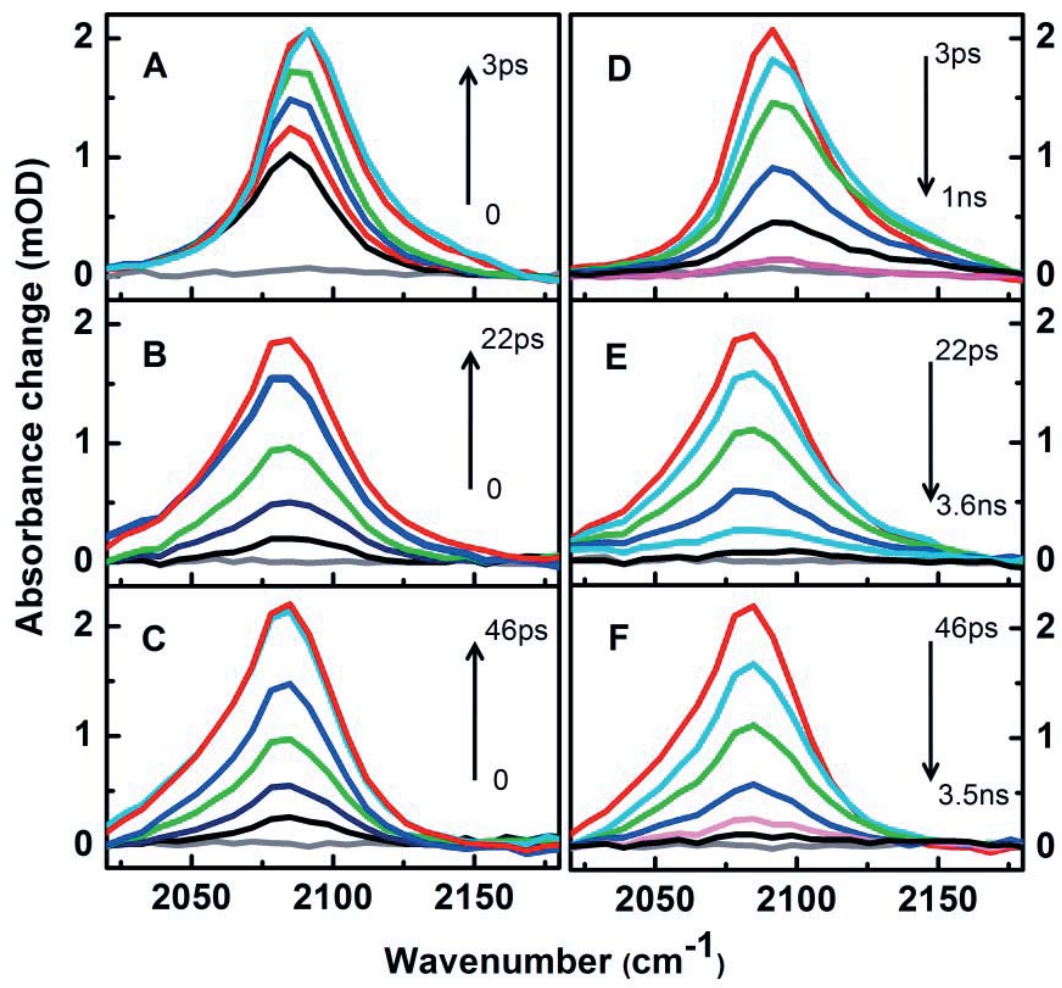

Figure 6. A, B, C: Mid-infrared transient absorption spectra of PEn-NDI series on short timescale. D, E, F: Mid-infrared transient absorption spectra of PEn-NDI series on longer timescale (see inset). The data were measured in $\mathrm{CH}_{2} \mathrm{Cl}_{2}$ solutions with excitation wavelength at $400 \mathrm{~nm}$. Optical density of sample solutions was controlled with $1 \mathrm{mOD}$ at $350 \mathrm{~nm}$ with a 350 $\mu \mathrm{m}$ spacer. Panels in left column show spectra with short time delays (increasing transient absorption) while panels in right column show spectra with longer time delays (transient absorption decay).

The dynamics of charge separation and recombination in the PEn-NDI oligomers were obtained by monitoring the kinetics at $2080 \mathrm{~cm}^{-1}$, and the results are shown in Figure 5B for comparison to the kinetics obtained by monitoring the visible transient absorption (Figure 5A). The rates obtained from analysis of the infrared transient absorption dynamics are tabulated in Table 3, and as can be seen they are in very good agreement with the rates obtained from the visible transient absorption. ${ }^{49}$

Table 3. Charge Separation and Recombination Dynamics in PEn-NDI Oligomers

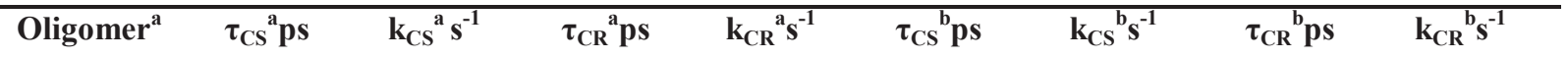




\begin{tabular}{ccccccccc}
\hline PE4-NDI & 1.0 & $1.0 \times 10^{12}$ & 316 & $3.2 \times 10^{9}$ & 1.0 & $1.0 \times 10^{12}$ & 446 & $2.2 \times 10^{9}$ \\
PE6-NDI & 2.3 & $4.3 \times 10^{11}$ & 1004 & $1.0 \times 10^{9}$ & 4.4 & $2.3 \times 10^{11}$ & 1123 & $8.9 \times 10^{8}$ \\
PE8-NDI & 8.4 & $1.2 \times 10^{11}$ & 1176 & $8.5 \times 10^{8}$ & 9.1 & $1.1 \times 10^{11}$ & 1005 & $1.0 \times 10^{9}$
\end{tabular}

${ }^{a}$ Lifetimes $\left(\tau_{\mathrm{CS}}\right.$ and $\left.\tau_{\mathrm{CR}}\right)$ were measured from femtosecond transient absorption spectroscopy(fs-TA) in dichloromethane, and rates $\left(\mathrm{k}_{\mathrm{CS}}\right.$ and $\left.\mathrm{k}_{\mathrm{CR}}\right)$ were calculated by $\mathrm{k}_{\mathrm{CS}}=1 / \tau_{\mathrm{CS}}$ and $\mathrm{k}_{\mathrm{CR}}=1 / \tau_{\mathrm{CR}}$. ${ }^{\mathrm{b}}$ Lifetimes $\left(\tau_{\mathrm{CS}}\right.$ and $\left.\tau_{\mathrm{CR}}\right)$ were measured from time resolved infrared (TRIR) spectroscopy in dichloromethane, and rates $\left(\mathrm{k}_{\mathrm{CS}}\right.$ and $\left.\mathrm{k}_{\mathrm{CR}}\right)$ were calculated by $\mathrm{k}_{\mathrm{CS}}=1 / \tau_{\mathrm{CS}}$ and $\mathrm{k}_{\mathrm{CR}}=1 / \tau_{\mathrm{CR}}$.

\section{Rates of Electron Transfer, Structure of the Charge Separated State, and Mechanisms.}

The findings reported here indicate that rapid photoinduced electron transfer occurs in a family of oligo(phenylene ethynylene) oligomers that are singly end-capped with a naphthalene diimide acceptor. Forward ET (charge separation) is strongly exothermic $\left(\Delta \mathrm{G}_{\mathrm{CS}} \sim-1.1 \mathrm{eV}\right)$ and the rates are correspondingly large $\left(\sim 10^{11} \mathrm{~s}^{-1}\right)$. Return ET (charge recombination) is even more exothermic $\left(\Delta \mathrm{G}_{\mathrm{CR}} \sim-2.0 \mathrm{eV}\right)$, yet the rates are considerably slower, in the range of $\sim 10^{9} \mathrm{~s}^{-1}$. The significant difference in forward and return ET rates likely stems from several factors. First, the driving force for forward ET is comparable to the reorganization energy $(\lambda)$, and as such, the reaction is nearly activationless, occurring at approximately the maximum rate for a non-adiabatic ET process $\left(\sim 10^{12} \mathrm{~s}^{-1}\right){ }^{50}$ By contrast, the very large exothermicity of the charge recombination process $(-2.0 \mathrm{eV})$, places this reaction well into the Marcus inverted region, and this likely in part accounts for the $\sim 100$ fold decrease in the rate compared to charge separation. ${ }^{1,50-51}$

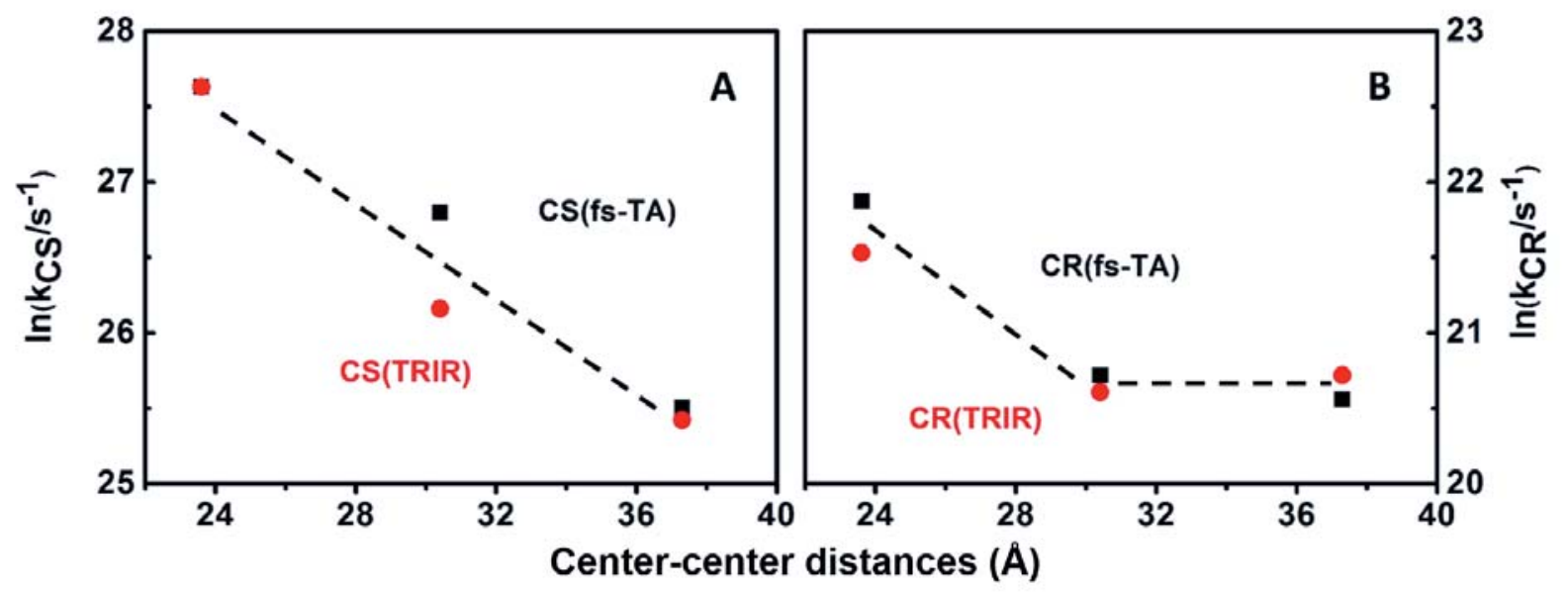

Figure 7. Distance dependence of charge separation (A) and charge recombination (B) for PEnNDI oligomers. $(\bullet)$ : rates measured by infrared transient absorption; $(\bullet)$ : rates measured by 
visible transient absorption. In part $\mathrm{A}$, dashed line $\left(\beta_{\mathrm{CS}}\right)$ has slope of $0.15 \AA^{-1}$. In part $\mathrm{B}$, negative sloped line is $\beta_{\mathrm{CR}} \sim 0.15 \AA^{-1}$.

Correlations of the rates of charge separation and recombination as a function of donoracceptor center-to-center separation distance provide further insight into the mechanism and distance dependence of charge transfer in the PEn-NDI series (Figure 7). The correlation shows that the forward ET rates decrease weakly with distance, and the correlation is consistent with a logarithmic rate decay, e.g, $\mathrm{k}_{\mathrm{CS}}=\mathrm{k}_{0} \exp (-\beta \mathrm{r})$, with $\beta_{\mathrm{CS}} \sim 0.15 \AA^{-1}$. By contrast, the rate for charge recombination does not decay monotonically with distance, rather it follows the sequence PE4NDI > PE6-NDI PE8-NDI. Note also that the decrease of rate between PE4-NDI and PE6-NDI is consistent with a distance dependence factor $\beta_{\mathrm{CR}} \sim 0.15 \AA^{-1}$, the same as the forward ET reaction, but $\mathrm{k}_{\mathrm{CR}}$ then is nearly constant $\left(\beta_{\mathrm{CR}} \sim 0\right)$ from PE6-NDI to PE8-NDI. A similar break in distance dependence has been observed in other donor-bridge-acceptor systems, and in these cases the change has been attributed to a crossover in the ET mechanism. ${ }^{9,52}$ As outlined below, we believe that a similar change in mechanism may occur for the return ET reactions in the PEnNDI series.

An analysis of the variation of the rates across the PEn-NDI series must account for the fact that the thermodynamics for forward and return ET are nearly independent of the length of the OPE segment (Table 2). Thus, the variation in rate with length must arise from variation(s) of other factors, e.g., electronic coupling, structure of the OPE polaron (cation radical state, $\mathrm{OPE}^{+\bullet}$ ) and/or conformational gating. Before pursuing the discussion further, we digress briefly to consider the structure and delocalization of the singlet excited state and the charge separated states in the PEn-NDI oligomers. Considerable previous work has explored the structure of the excited states in $\pi$-conjugated oligomers, and most pertinent to this discussion is oligo(phenylene ethynylene)s. In this regard it has been established that the effective conjugation length in the singlet excited state is approximately 9 phenylene ethynylene (PE) repeating units. ${ }^{53-55}$ By contrast, less is known regarding the structure of the positive polaron state (cation radical) of OPEs. In the current study it was found that the absorption of the cation state of the OPEs does not vary significantly with oligomer length, from PE4 to PE8 (Figure 3C). This finding suggests that the hole polaron is relatively more localized than the singlet state, perhaps effectively occupying a confined segment of $\mathrm{n} \leq 4$ repeat units in the longer oligomers. 
With this background, we present the model shown in Scheme 2 to discuss and explain the trends in ET rates observed in the PEn-NDI oligomers. Excitation of PEn-NDI produces a singlet state that is delocalized over the entire oligomer. The rate of charge separation depends on the coupling between the singlet wavefunction on the PEn donor and the NDI acceptor. The small decrease in forward ET rate with increasing oligomer length $\left(\beta \sim 0.15 \AA^{-1}\right)$ is attributed to a decrease in the electronic coupling that occurs because the excited state wave function is more delocalized as the oligomer length increases. However, because the PEn hole polaron is more spatially confined than the singlet exciton, the distance dependence of charge recombination in the charge separated state may involve a more complicated scheme. Here we propose the possible involvement of different charge separated (CT) states that may exist in the longer oligomers. As shown in Scheme 2, forward ET produces an initial "geminate CT" state, where the hole polaron is localized on the OPE segment closest to the NDI acceptor. While there clearly is a Coulombic attraction between the electron and hole in this state, due to the long lifetime of the CT state, it is possible that the polaron could "hop" along the chain to form one or more distinct "separated CT" states, where the polaron has moved along the OPE segment away from the NDI acceptor. We estimate that in $\mathrm{CH}_{2} \mathrm{Cl}_{2}$ the Coulombic barrier between the geminate and separated CT states is $<0.07 \mathrm{eV}$. Given that the energy barrier to hopping is relatively low, the rate of the polaron hopping is most likely controlled by fluctuations in the conformation of the OPE backbone, more specifically polaron hopping is conformationally gated by rotations of the phenylene units. Within this model, the rate of return ET may be controlled in part by conformation gating of the hole hopping which interconverts the separated CT state(s) and the geminate CT state. This could explain why the rates for return ET are comparable in the longer oligomers.

\section{Scheme 2}




\section{CONCLUSION}

A series of naphthalene diimide derivative (NDI) end capped conjugated oligomers (PEn-NDI) were prepared, where the conjugation length of oligo(phenylene ethynylene) (OPE) conjugated backbone was controlled by Sonogashira reactions. The oligomers systematically investigated by electrochemistry and steady-state and time resolved spectroscopy. Electron transfer is the dominant pathway for deactivating of excited states of the PEn-NDI oligomers, with an efficiency $>97 \%$. Both charge separation and charge recombination are strongly exothermic $\left(\Delta \mathrm{G}_{\mathrm{CS}}^{0} \sim-1.10\right.$ and $\left.\Delta \mathrm{G}_{\mathrm{CR}}^{0} \sim-2.00 \mathrm{eV}\right)$, and the thermodynamics do not vary much across the series. By using UV-visible region femtosecond transient absorption spectroscopy and midinfrared transient absorption spectroscopy to probe the excited-state and charge transfer dyanamics, the PEn-NDI oligomers are shown to undergo charge separation on the $1-10 \mathrm{ps}$ timescale, and then slower charge recombination on timescales 1- 5 ns. The forward CS rates decrease weakly with distance $\left(\beta_{\mathrm{CS}} \sim 0.15 \AA^{-1}\right)$, caused by the decrease in the electronic coupling. More interestingly, a discontinuous distance dependence was observed for CR, suggesting a change in the mechanism for the return electron transfer.

\section{ASSOCIATED CONTENT}

\section{Supporting Information}

Detailed description of synthesis, characterization, electrochemistry, transient absorption and ground state FT-IR data can be found in the supporting information. This material is available free of charge via the Internet at http://pubs.acs.org. 


\section{AUTHOR INFORMATION}

\section{Corresponding Author}

*E-mail: kirk.schanze@utsa.edu

*E-mail: omar.abdelsaboor@kaust.edu.sa

\section{Author Contributions}

The manuscript was written through contributions of all authors. All authors have given approval to the final version of the manuscript.

\section{Notes}

The authors declare no competing financial interest.

\section{ACKNOWLEDGMENT}

This work was partially supported by the National Science Foundation (Grant No. CHE1504727). KSS also acknowledges the Welch Foundation for support. We also acknowledge many insightful discussions with John R. Miller (Brookhaven National Laboratory) which in part stimulated this work.

\section{REFERENCES}

1. Closs, G. L.; Miller, J. R., Intramolecular Long-Distance Electron Transfer in Organic Molecules. Science 1988, 240, 440-447.

2. Fox, M. A.; Chanon, M., Photoinduced Electron Transfer, Parts A - D. Elsevier: Amsterdam.

3. Wasielewski, M. R., Photoinduced Electron Transfer in Supramolecular Systems for Artificial Photosynthesis. Chem. Rev. 1992, 92, 435-461.

4. Hagfeldt, A.; Boschloo, G.; Sun, L.; Kloo, L.; Pettersson, H., Dye-Sensitized Solar Cells. Chem. Rev. 2010, 110, 6595-6663. 
5. Günes, S.; Neugebauer, H.; Sariciftci, N. S., Conjugated Polymer-Based Organic Solar Cells. Chem. Rev. 2007, 107, 1324-1338.

6. Brennaman, M. K.; Dillon, R. J.; Alibabaei, L.; Gish, M. K.; Dares, C. J.; Ashford, D. L.; House, R. L.; Meyer, G. J.; Papanikolas, J. M.; Meyer, T. J., Finding the Way to Solar Fuels with Dye-Sensitized Photoelectrosynthesis Cells. J. Am. Chem. Soc. 2016, 138, 1308513102.

7. Gilbert, M.; Albinsson, B., Photoinduced Charge and Energy Transfer in Molecular Wires. Chem. Soc. Rev. 2015, 44, 845-862.

8. Balzani, V.; Credi, A.; Venturi, M., Molecular Devices and Machines. Nano Today 2007, 2, $18-25$.

9. Weiss, E. A.; Ahrens, M. J.; Sinks, L. E.; Gusev, A. V.; Ratner, M. A.; Wasielewski, M. R., Making a Molecular Wire: Charge and Spin Transport Through para-Phenylene Oligomers. J. Am. Chem. Soc. 2004, 126, 5577-5584.

10. Wiberg, J.; Guo, L.; Pettersson, K.; Nilsson, D.; Ljungdahl, T.; Martensson, J.; Albinsson, B., Charge Recombination Versus Charge Separation in Donor-Bridge-Acceptor Systems. J. Am. Chem. Soc. 2007, 129, 155-163.

11. Pettersson, K.; Wiberg, J.; Ljungdahl, T.; Martensson, J.; Albinsson, B., Interplay between Barrier Width and Height in Electron Tunneling: Photoinduced Electron Transfer in Porphyrin-Based Donor-Bridge-Acceptor Systems. J. Phys. Chem. A 2006, 110, 319-326.

12. Davis, W. B.; Svec, W. A.; Ratner, M. A.; Wasielewski, M. R., Molecular-Wire Behaviour in P-Phenylenevinylene Oligomers. Nature 1998, 396, 60-63. 
13. de la Torre, G.; Giacalone, F.; Segura, J. L.; Martin, N.; Guldi, D. M., Electronic Communication through Pi-Conjugated Wires in Covalently Linked Porphyrin/C-60 Ensembles. Chem. Eur. J. 2005, 11, 1267-1280.

14. Armaroli, N.; Barigelletti, F.; Ceroni, P.; Eckert, J. F.; Nicoud, J. F.; Nierengarten, J. F., Photoinduced Energy Transfer in a Fullerene-Oligophenylenevinylene Conjugate. Chem. Commun. 2000, 599-600.

15. Albinsson, B.; Eng, M. P.; Pettersson, K.; Winters, M. U., Electron and Energy Transfer in Donor-Acceptor Systems with Conjugated Molecular Bridges. Phys. Chem. Chem. Phys. 2007, 9, 5847-5864.

16. Goldsmith, R. H.; Sinks, L. E.; Kelley, R. F.; Betzen, L. J.; Liu, W. H.; Weiss, E. A.; Ratner, M. A.; Wasielewski, M. R., Wire-Like Charge Transport at near Constant Bridge Energy through Fluorene Oligomers. Proc. Natl. Acad. Sci. U.S.A. 2005, 102, 3540-3545.

17. Miura, T.; Carmieli, R.; Wasielewski, M. R., Time-Resolved Epr Studies of Charge Recombination and Triplet-State Formation within Donor-Bridge-Acceptor Molecules Having Wire-Like Oligofluorene Bridges. J. Phys. Chem. A 2010, 114, 5769-5778.

18. Atienza-Castellanos, C.; Wielopolski, M.; Guldi, D. M.; van der Pol, C.; Bryce, M. R.; Filippone, S.; Martin, N., Determination of the Attenuation Factor in Fluorene-Based Molecular Wires. Chem. Commun. 2007, 5164-5166.

19. Regehly, M.; Wang, T. Y.; Siggel, U.; Fuhrhop, J. H.; Roeder, B., Electron Transfer in Oligothiophene-Bridged Bisporphyrins. J. Phys. Chem. B 2009, 113, 2526-2534.

20. van Hal, P. A.; Knol, J.; Langeveld-Voss, B. M. W.; Meskers, S. C. J.; Hummelen, J. C.; Janssen, R. A. J., Photoinduced Energy and Electron Transfer in Fullerene-Oligothiophene-Fullerene Triads. J. Phys. Chem. A 2000, 104, 5974-5988. 
21. Eckert, J.-F.; Nicoud, J.-F.; Nierengarten, J.-F.; Liu, S.-G.; Echegoyen, L.; Barigelletti, F.; Armaroli, N.; Ouali, L.; Krasnikov, V.; Hadziioannou, G., Fullerene-Oligophenylenevinylene Hybrids: Synthesis, Electronic Properties, and Incorporation in Photovoltaic Devices. J. Am. Chem. Soc. 2000, 122, 7467-7479.

22. Peeters, E.; van Hal, P. A.; Knol, J.; Brabec, C. J.; Sariciftci, N. S.; Hummelen, J. C.; Janssen, R. A. J., Synthesis, Photophysical Properties, and Photovoltaic Devices of Oligo(PPhenylene Vinylene)-Fullerene Dyads. J. Phys. Chem. B 2000, 104, 10174-10190.

23. Ramos, A. M.; Meskers, S. C. J.; van Hal, P. A.; Knol, J.; Hummelen, J. C.; Janssen, R. A. J., Photoinduced Multistep Energy and Electron Transfer in an Oligoaniline-Oligo(PPhenylene Vinylene)-Fullerene Triad. J. Phys. Chem. A 2003, 107, 9269-9283.

24. Clifford, J. N.; Gu, T.; Nierengarten, J. F.; Armaroli, N., Photoinduced Energy and Electron Transfer in Fullerene-Oligophenyleneethynylene Systems: Dependence on the Substituents of the Oligomer Unit. Photochem. Photobiol. Sci 2006, 5, 1165-1172.

25. Miura, T.; Tao, R.; Shibata, S.; Umeyama, T.; Tachikawa, T.; Imahori, H.; Kobori, Y., Geometries, Electronic Couplings, and Hole Dissociation Dynamics of Photoinduced Electron-Hole Pairs in Polyhexylthiophene-Fullerene Dyads Rigidly Linked by Oligophenylenes. J. Am. Chem. Soc. 2016, 138, 5879-5885.

26. Keller, J. M.; Glusac, K. D.; Danilov, E. O.; McIlroy, S.; Sreearuothai, P.; Cook, A. R.; Jiang, H.; Miller, J. R.; Schanze, K. S., Negative Polaron and Triplet Exciton Diffusion in Organometallic Molecular Wires;. J. Am. Chem. Soc. 2011, 133, 11289-11298.

27. Keller, J. M.; Schanze, K. S., Synthesis of Monodisperse Platinum Acetylide Oligomers End-Capped with Naphthalene Diimide Units. Organometallics 2009, 28, 4210-4216. 
28. Greenfield, S. R.; Svec, W. A.; Gosztola, D.; Wasielewski, M. R., Multistep Photochemical Charge Separation in Rod-Like Molecules Based on Aromatic Imides and Diimides. J. Am. Chem. Soc. 1996, 118, 6767-6777.

29. Liu, H.; Ye, T.; Mao, C., Fluorescent Carbon Nanoparticles Derived from Candle Soot. Angew. Chem. Int. Ed. 2007, 46, 6473-6475.

30. Wilkinson, F.; Helman, W. P.; Ross, A. B., Rate Constants for the Decay and Reactions of the Lowest Electronically Excited Singlet-State of Molecular-Oxygen in Solution. An Expanded and Revised Complication. J. Phys. Chem. Ref. Data 1995, 24, 663-1021.

31. Farley, R. T., Photophysics of Platinum and Iridium Organometallic Materials from Molecular Wires to Nonlinear Optics. Ph.D. Dissertation. University of Florida, 2007.

32. El-Ballouli, A. O.; Alarousu, E.; Bernardi, M.; Aly, S. M.; Lagrow, A. P.; Bakr, O. M.; Mohammed, O. F., Quantum Confinement-Tunable Ultrafast Charge Transfer at the PbS Quantum Dot and Phenyl-C-61-Butyric Acid Methyl Ester Interface. J. Am. Chem. Soc. 2014, 136, 6952-6959.

33. Alsam, A. A.; Aly, S. M.; Usman, A.; Parida, M. R.; Del Gobbo, S.; Alarousu, E.; Mohammed, O. F., Bimolecular Excited-State Electron Transfer with Surprisingly LongLived Radical Ions. J. Phys. Chem. C 2015, 119, 21896-21903.

34. Guo, X. F.; Gan, Z. H.; Luo, H. X.; Araki, Y.; Zhang, D. Q.; Zhu, D. B.; Ito, O., Photoinduced Electron-Transfer Processes of Tetrathiafulvalene-(Spacer)(Naphthalenediimide)-(Spacer)-Tertrathiafulv Alene Triads in Solution. J. Phys. Chem. A 2003, 107, 9747-9753.

35. Banerji, N.; Duvanel, G.; Perez-Velasco, A.; Maity, S.; Sakai, N.; Matile, S.; Vauthey, E., Excited-State Dynamics of Hybrid Multichromophoric Systems: Toward an Excitation 
Wavelength Control of the Charge Separation Pathways. J. Phys. Chem. A 2009, 113, 82028212.

36. Tang, Y. L.; Hill, E. H.; Zhou, Z. J.; Evans, D. G.; Schanze, K. S.; Whitten, D. G., Synthesis, Self-Assembly, and Photophysical Properties of Cationic Oligo(pPhenyleneethynylene)s. Langmuir 2011, 27, 4945-4955.

37. Tang, Y. L.; Corbitt, T. S.; Parthasarathy, A.; Zhou, Z. J.; Schanze, K. S.; Whitten, D. G., Light-Induced Antibacterial Activity of Symmetrical and Asymmetrical Oligophenylene Ethynylenes. Langmuir 2011, 27, 4956-4962.

38. Sudeep, P. K.; James, P. V.; Thomas, K. G.; Kamat, P. V., Singlet and Triplet Excited-State Interactions and Photochemical Reactivity of Phenyleneethynylene Oligomers. J. Phys. Chem. A 2006, 110, 5642-5649.

39. Benniston, A. C.; Harriman, A., Dynamics of Charge-Transfer and Recombination in a Covalently-Linked, Face-to-Face Electron Donor-Acceptor Complex. J. Am. Chem. Soc. 1994, 116, 11531-11537.

40. Cody, J.; Mandal, S.; Yang, L.; Fahrni, C. J., Differential Tuning of the Electron Transfer Parameters in 1,3,5-Triarylpyrazolines: A Rational Design Approach for Optimizing the Contrast Ratio of Fluorescent Probes. J. Am. Chem. Soc. 2008, 130, 13023-13032.

41. Kohler, A.; Wilson, J. S.; Friend, R. H.; Al-Suti, M. K.; Khan, M. S.; Gerhard, A.; Bassler, H., The Singlet-Triplet Energy Gap in Organic and Pt-Containing Phenylene Ethynylene Polymers and Monomers. J. Chem. Phys 2002, 116, 9457-9463.

42. Kosower, E. M.; Cotter, J. L., Stable Free Radicals. 2. Reduction of 1-Methyl-4Cyanopyridinium Ion to Methylviologen Cation Radical. J. Am. Chem. Soc. 1964, 86, 55245527. 
43. $\mathrm{MV}^{+}$. displays two absorptions, a narrow band at $395 \mathrm{~nm}\left(\varepsilon=30,000 \mathrm{M}^{-1} \mathrm{~cm}^{-1}\right)$ and a broad band at $600 \mathrm{~nm}\left(\varepsilon=10,000 \mathrm{M}^{-1} \mathrm{~cm}^{-1}\right)$, see ref. 42 . The $395 \mathrm{~nm}$ feature is clearly observed in all of the spectra of the products of the bimolecular electron transfer reaction (eq. 6, see Figure 3). Given that the $395 \mathrm{~nm} \mathrm{MV}^{+}$band is 3 times more intense compared to the 600 $\mathrm{nm}$ feature, and that the experimental absorption that is seen in Figure 3 at $585 \mathrm{~nm}$ is 2 to 3 times stronger than the $395 \mathrm{~nm} \mathrm{MV}^{+}$band, it is clear that the long wavelength band is almost entirely due to the OPE cation radical, $\mathrm{OPE}^{+}$. Moreover, the results suggest that the OPE cation state absorptivity is $>40,000 \mathrm{M}^{-1} \mathrm{~cm}^{-1}$.

44. Funston, A. M.; Silverman, E. E.; Miller, J. R.; Schanze, K. S., Charge Transfer through Terthiophene End-Capped poly(Arylene Ethynylene)s. J. Phys. Chem. B 2004, 108, $1544-$ 1555.

45. Duvanel, G.; Grilj, J.; Schuwey, A.; Gossauer, A.; Vauthey, E., Ultrafast Excited-State Dynamics of Phenyleneethynylene Oligomers in Solution. Photochem. Photobiol. Sci 2007, $6,956-963$.

46. Gabrielsson, A.; Hartl, F.; Zhang, H.; Smith, J. R. L.; Towrie, M.; Vlcek, A.; Perutz, R. N., Ultrafast Charge Separation in a Photoreactive Rhenium-Appended Porphyrin Assembly Monitored by Picosecond Transient Infrared Spectroscopy. J. Am. Chem. Soc. 2006, 128, 4253-4266.

47. Polyansky, D. E.; Danilov, E. O.; Voskresensky, S. V.; Rodgers, M. A. J.; Neckers, D. C., Delocalization of Free Electron Density through Phenylene-Ethynylene: Structural Changes Studied by Time-Resolved Infrared Spectroscopy. J. Am. Chem. Soc. 2005, 127, 1345213453. 
48. Mohammed, O. F.; Adamczyk, K.; Banerji, N.; Dreyer, J.; Lang, B.; Nibbering, E. T. J.; Vauthey, E., Direct Femtosecond Observation of Tight and Loose Ion Pairs Upon Photoinduced Bimolecular Electron Transfer. Angew. Chem. Int. Ed. 2008, 47, 9044-9048.

49. There is a "fast phase" in the decay kinetics for the $2080 \mathrm{~cm}^{-1}$ signal for PE4-NDI. This component is not matched in the visible transient absorption kinetics for the same compound. The origin of the fast phase is not clear, but it could be associated with an intramolecular structural reorganization in the charge separated state.

50. Marcus, R. A.; Sutin, N., Electron Transfers in Chemistry and Biology. Biochim. Biophys. Acta 1985, 811, 265-322.

51. Wasielewski, M. R.; Niemczyk, M. P.; Svec, W. A.; Pewitt, E. B., Dependence of Rate Constants for Photoinduced Charge Separation and Dark Charge Recombination on the Free-Energy of Reaction in Restricted-Distance Porphyrin Quinone Molecules. J. Am. Chem. Soc 1985, 107, 1080-1082.

52. Lewis, F. D.; Zhu, H. H.; Daublain, P.; Fiebig, T.; Raytchev, M.; Wang, Q.; Shafirovich, V., Crossover from Superexchange to Hopping as the Mechanism for Photoinduced Charge Transfer in DNA Hairpin Conjugates. J. Am. Chem. Soc. 2006, 128, 791-800.

53. Sluch, M. I.; Godt, A.; Bunz, U. H. F.; Berg, M. A., Excited-State Dynamics of Oligo(PPhenyleneethynylene): Quadratic Coupling and Torsional Motions. J. Am. Chem. Soc. 2001, $123,6447-6448$.

54. Ziener, U.; Godt, A., Synthesis and Characterization of Monodisperse Oligo(Phenyleneethynylene)s. J. Org. Chem. 1997, 62, 6137-6143. 
55. Kukula, H.; Veit, S.; Godt, A., Synthesis of Monodisperse Oligo(ParaPhenyleneethynylene)S Using Orthogonal Protecting Groups with Different Polarity for Terminal Acetylene Units. Eur. J. Org. Chem. 1999, 277-286.

\section{TOC Graphic}

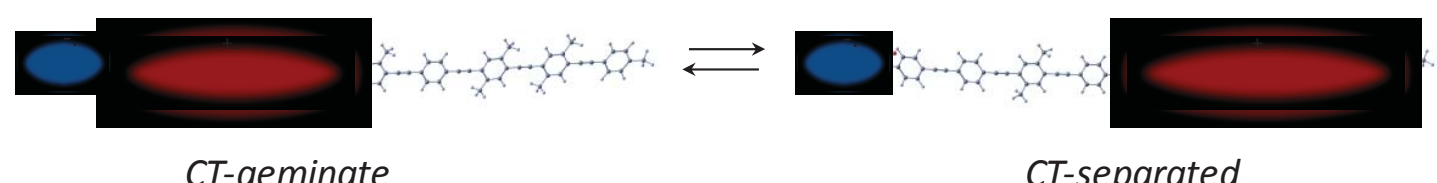

CT-geminate

CT-separated

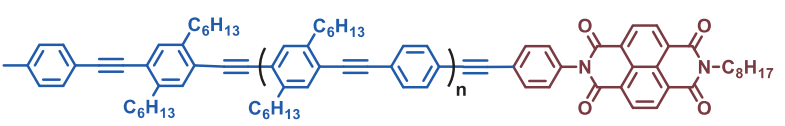

